Anil Sapru

Martha A. Q. Curley

Sandra Brady

Michael A. Matthay

Heidi Flori

\section{Elevated PAI-1 is associated with poor clinical outcomes in pediatric patients with acute lung injury}

Received: 28 March 2009

Accepted: 15 September 2009

Published online: 24 October 2009

(C) The Author(s) 2009. This article is published with open access at Springerlink.com

This work was presented in part at the Society for Pediatric Research Annual Meeting, Honolulu, Hawaii, May 2008.

\author{
A. Sapru (凶) \\ Division of Critical Care Medicine, \\ Department of Pediatrics, \\ University of California, San Francisco, \\ Box 0106, San Francisco, CA 94143, USA \\ e-mail: anil.sapru@ucsf.edu \\ Tel.: +1-415-4760963 \\ Fax: +1-415-5024186 \\ M. A. Q. Curley \\ School of Nursing, \\ University of Pennsylvania, \\ Philadelphia, PA, USA \\ S. Brady - M. A. Matthay \\ Cardiovascular Research Institute, \\ University of California, San Francisco, \\ San Francisco, CA, USA \\ M. A. Matthay \\ Department of Medicine and Anesthesia, \\ University of California, San Francisco, \\ San Francisco, CA, USA
}

H. Flori

Pediatric Critical Care, Children's Hospital and Research Center, Oakland, CA, USA

\begin{abstract}
Purpose: Deposition of fibrin in the alveolar space is a hallmark of acute lung injury (ALI). Plasminogen activator inhibitor-1 (PAI-1) is an antifibrinolytic agent that is activated during inflammation. Increased plasma and pulmonary edema fluid levels of PAI-1 are associated with increased mortality in adults with ALI. This relationship has not been examined in children. The objective of this study was to test whether increased plasma PAI-1 levels are associated with worse clinical outcomes in pediatric patients with ALI. Design/methods: We measured plasma PAI-1 levels on the first day of ALI among 94 pediatric patients enrolled in two separate prospective, multicenter investigations and followed them for clinical outcomes. All patients met American European Consensus Conference criteria for ALI. Results: A total of 94 patients were included. The median age was 3.2 years (range 16 days-
\end{abstract}

18 years), the $\mathrm{PaO}_{2} / \mathrm{F}_{\mathrm{i}} \mathrm{O}_{2}$ was $141 \pm 72$ (mean $\pm \mathrm{SD}$ ), and overall mortality was $14 / 94$ (15\%). PAI-1 levels were significantly higher in nonsurvivors compared to survivors $(P<0.01)$. The adjusted odds of mortality doubled for every $\log$ increase in the level of plasma PAI-1 after adjustment for age and severity of illness. Conclusions: Higher PAI-1 levels are associated with increased mortality and fewer ventilator-free days among pediatric patients with ALI. These findings suggest that impaired fibrinolysis may play a role in the pathogenesis of ALI in pediatric patients and suggest that PAI-1 may serve as a useful biomarker of prognosis in patients with ALI.

Keywords Accurate respiratory distress syndrome $\cdot$ Acute lung injury · Clinical studies · Pediatrics · Plasminogen activator inhibitor-1 (PAI-1)

\section{Introduction}

Acute lung injury (ALI) is a life-threatening disorder characterized by severe inflammation in the lungs and frequently by the occurrence of multiple organ failure [1]. ALI is a major cause of morbidity and mortality among critically ill children and accounts for approximately $1-4 \%$ of all pediatric intensive care unit (PICU) admissions; up to $8 \%$ of all mechanically ventilated children meet criteria for ALI. There are both similarities and significant differences in the predisposing causes and clinical course of ALI in adults and children [2-7]. The reported mortality from ALI 
in the pediatric age group overall ranges from 8 to $60 \%$ with higher mortality reported among immunocompromised children [2-8]. The only therapy that has been proven to reduce mortality in ALI in adults is the use of lungprotective ventilatory strategy [1]. Insight into pathophysiological derangements that characterize early clinical ALI in children may help in identifying patients at greatest risk and guide the development of new therapies for this devastating disorder.

The pathophysiology of ALI is characterized by disruption of the lung endothelial and alveolar epithelial barriers, translocation of protein-rich edema fluid into the alveoli, release of pro-inflammatory cytokines, and deposition of fibrin in the alveolar space [9]. The deposition of fibrin in the alveoli is the net result of an alteration in the balance of coagulation and fibrinolysis. Early in the course of ALI, there is elevation of PAI-1 activity in plasma and air spaces, which is accompanied by a decrease in alveolar fibrinolysis [10-14]. Excessive fibrin deposition enhances inflammatory responses by activating endothelial cells to produce pro-inflammatory mediators and increases lung vascular permeability [15]. Therefore, assessing the extent of fibrinolysis in ALI may be important from a pathogenetic and prognostic standpoint [9].

Previous studies in adults with ALI have reported that an early increase in plasma levels of PAI-1 is an independent risk factor for mortality and adverse clinical outcomes and therefore, measurement of PAI-1 may be useful to (a) identify those at highest risk of adverse clinical outcomes, and (b) lead to the development of new therapies $[9,13,16]$. There have been no studies to date examining the relationship of plasma PAI-1 levels to clinical outcomes in pediatric patients with ALI. It is not clear whether the association of elevated PAI-1 levels with increased mortality described in adults is true for pediatric patients as well because there are significant differences between adults and children in terms of (1) predisposing conditions leading to ALI, (2) mortality from ALI, and (3) response to therapy with activated protein $\mathrm{C}$ in patients with sepsis, which is a common predisposing cause of ALI. Therefore, in order to test the relationship between plasma levels of PAI-1 and mortality, we hypothesized that early elevation of plasma PAI-1 would be associated with increased mortality and fewer ventilator-free days in pediatric patients with ALI.

\section{Methods}

Human subjects

The study was carried out on pediatric patients with ALI enrolled in two clinical trials of ALI.
1. Prospective observational trial of ALI in pediatric patients with ALI. A total of 320 patients with ALI, age 1 month to 18 years, were enrolled at Children's Hospital and Research Center, Oakland, CA, USA (CHRCO) and University of California, San Francisco (UCSF) Children's Hospital, USA. The overall mortality in the cohort was $22 \%$ [4]. Plasma samples were obtained from 72 patients within $24 \mathrm{~h}$ of development of ALI.

2. Randomized clinical trial of prone positioning in the management of pediatric patients with ALI. A total of 102 patients with ALI, age 2 weeks to 18 years were enrolled from seven U.S. PICUs including CHRCO and UCSF Children's Hospital. Patients were randomized to the supine or prone position. The primary outcome was the number of ventilator-free days. There was no difference in the number of ventilator-free days in the two arms and overall. The overall mortality in this trial was $8 \%$ [2]. Plasma samples were obtained within $24 \mathrm{~h}$ of development of ALI from 22 patients in this trial.

Both of these studies prospectively identified and enrolled pediatric patients meeting the standard American European Consensus Conference (AECC) criteria for ALI [17]. The AECC criteria for definition of ALI are $\mathrm{PaO}_{2} /$ $\mathrm{F}_{\mathrm{i}} \mathrm{O}_{2}<300$, bilateral opacities on the chest radiograph, and either a pulmonary wedge pressure of less than $18 \mathrm{mmHg}$ or the absence of clinical evidence of left atrial hypertension.

The research featured here is based on a subset of ALI patients enrolled in the two studies. We could not include all of the enrolled patients in the parent studies because collection of blood samples was not originally a part of either of the primary studies. This study was added on as an ancillary study to test the pathogenetic and prognostic value of biological markers in ALI. Blood samples could be collected only in a subset of patients because (1) the ancillary study with collection of blood samples from enrolled patients started after the studies were under way, (2) collection of blood samples was limited to centers that participated in the ancillary study, and (3) collection of blood samples was possible only for patients in whom consent for blood collection could be obtained. We included all 94 patients from the two studies who had a plasma sample collected within $24 \mathrm{~h}$ of meeting criteria for the diagnosis of ALI.

There was no difference in ventilator strategies between the ALI patients who had blood samples collected for the biomarker studies and those who did not. Study guidelines based on current best practice were followed for ventilator management and extubation in the interventional trial of prone positioning. In the ALI observational trial, ventilator management was as per the physician's preference, but a protocol was followed to guide the timing of extubation. However, management 
decisions were made by clinicians blinded to PAI-1 levels and therefore are unlikely to have led to any bias.

\section{Data collection}

Patient demographics, overall clinical status at onset of ALI, pediatric risk of mortality (PRISM) III score, diagnosis associated with the onset of $\mathrm{ALI}, \mathrm{PaO}_{2} / \mathrm{F}_{\mathrm{i}} \mathrm{O}_{2}$, chest radiograph findings, duration of mechanical ventilation, and 28-day all cause in-hospital mortality were collected at enrollment and during the hospital stay. Patients were followed for 28 days or in-hospital death.

\section{Measurements}

Plasma PAI-1 levels were measured on samples drawn within $24 \mathrm{~h}$ after meeting criteria for ALI. Plasma PAI-1 was measured using a standard ELISA technique with plates and reagents supplied by American Diagnostics, Greenwich, CT, USA. The protocol was performed essentially as recommended by the manufacturers and as published [18].

\section{Outcomes}

The primary outcome was mortality at 28 days and the secondary outcome was ventilator-free days (VFD).
Data analysis

Normally distributed data are presented as mean and SD and non-normally distributed data are presented as median and ranges. We compared non-normally distributed continuous variables using the nonparametric Spearman's correlation test. We also compared VFD across ordered categories of plasma PAI-1 levels using the test for trend across ordered categories. We used regression models to control for the potential confounding effect of age and severity of illness on mortality and VFD. Due to their right skewed distribution, and as has been done in previous studies, we log-transformed PAI-1 levels prior to carrying out parametric tests to compare PAI-1 levels within groups and for regression analysis. The statistical analysis was carried out on Stata 9 software (Stata, College Station, TX, USA).

\section{Results}

A total of 94 patients were available to us for this study. The baseline characteristics and primary diagnoses predisposing to ALI among these patients are shown in Table1.

Since the present study includes only those patients from whom blood samples were collected within the first $24 \mathrm{~h}$ of diagnosis of ALI, we compared the baseline characteristics among patients having blood samples with

Table 1 Baseline characteristics of 94 patients with ALI included in the current study and of patients enrolled in the parent studies

\begin{tabular}{|c|c|c|c|c|c|c|c|c|}
\hline & \multicolumn{3}{|c|}{ (A) ALI observational study } & \multicolumn{3}{|c|}{ (B) Prone positioning study } & \multicolumn{2}{|l|}{ Current study } \\
\hline & $\begin{array}{l}\text { Overall } \\
\text { cohort }(n=320)\end{array}$ & $\begin{array}{l}\text { Included } \\
\text { here }(n=72)\end{array}$ & $P$ & $\begin{array}{l}\text { Overall } \\
\text { cohort }(n=101)\end{array}$ & $\begin{array}{l}\text { Included } \\
\text { here }(n=22)\end{array}$ & $P$ & $\begin{array}{l}\text { Included } \\
\text { here }(\mathrm{A}+\mathrm{B}) \\
(n=94)\end{array}$ & $P$ \\
\hline Age (years) & $3.4(0-18)$ & $3.2(0.5-18)$ & 0.7 & $2.1(0.3-11)$ & $4.1(0.04-17)$ & & $3.2(0.04-18)$ & 0.5 \\
\hline Male & $57 \%$ & $51 \%$ & 0.4 & $52 \%$ & $54 \%$ & 0.8 & $49(52 \%)$ & 0.8 \\
\hline \multicolumn{9}{|l|}{ Race } \\
\hline Caucasian & $38 \%$ & $40 \%$ & 0.5 & $55 \%$ & $35 \%$ & 0.08 & $35(39 \%)$ & 0.7 \\
\hline Hispanic & $18 \%$ & $23 \%$ & & $24 \%$ & $20 \%$ & & $20(22 \%)$ & \\
\hline African American & $22 \%$ & $21 \%$ & & $11 \%$ & $35 \%$ & & $22(24 \%)$ & \\
\hline Asian & $8 \%$ & $4 \%$ & & $4 \%$ & $0 \%$ & & $3(3 \%)$ & \\
\hline Other/unknown & $15 \%$ & $11 \%$ & & $6 \%$ & $10 \%$ & & $10(11 \%)$ & \\
\hline \multicolumn{9}{|c|}{ Primary diagnosis associated with ALI } \\
\hline Pneumonia & $20 \%$ & $33 \%$ & 0.1 & $56 \%$ & $45 \%$ & 0.6 & $34(36 \%)$ & 0.2 \\
\hline Viral/bronchitis & $17 \%$ & $18 \%$ & & $14 \%$ & $18 \%$ & & $17(18 \%)$ & \\
\hline Aspiration & $15 \%$ & $14 \%$ & & $11 \%$ & $18 \%$ & & $14(15 \%)$ & \\
\hline Sepsis and meningitis & $14 \%$ & $14 \%$ & & $15 \%$ & $18 \%$ & & $14(15 \%)$ & \\
\hline Others & $33 \%$ & $21 \%$ & & $5 \%$ & $0 \%$ & & $15(16 \%)$ & \\
\hline \multicolumn{9}{|l|}{ Physiological variables } \\
\hline $\mathrm{PaO}_{2} / \mathrm{F}_{\mathrm{i}} \mathrm{O}_{2}$ & $161 \pm 74$ & $145 \pm 74$ & 0.09 & $100 \pm 65$ & $125 \pm 64$ & 0.1 & $141 \pm 72$ & 0.2 \\
\hline PRISM III (unadjusted) & $10 \pm 9$ & $10 \pm 6$ & 1 & $11 \pm 8$ & $11 \pm 8$ & 0.96 & $10 \pm 7$ & 0.6 \\
\hline Oxygenation index & $10 \pm 10$ & $12 \pm 12$ & 0.07 & $16 \pm 11$ & $15 \pm 10$ & 0.31 & $13 \pm 12$ & 0.4 \\
\hline
\end{tabular}

Data are expressed as median (range), mean $\pm \mathrm{SD}$, or $n(\%)$ 
patients in the entire cohort in each of the parent studies (Table 1). For the 72 patients drawn from the ALI observational study, the $\mathrm{PaO}_{2} / \mathrm{F}_{\mathrm{i}} \mathrm{O}_{2}$ was $145 \pm 74$, PRISM score was $10 \pm 6$, and the VFDs were $14 \pm 10$. These data are not statistically different from the values reported for the overall cohort in the parent study (Table 1) [4]. Among the 22 patients drawn from the prone positioning trial, the $\mathrm{PaO}_{2} / \mathrm{F}_{\mathrm{i}} \mathrm{O}_{2}$ was $125 \pm 64$, the PRISM score was $11 \pm 9$, and the VFDs were $15 \pm 8$. These data are not statistically different from the values reported for the overall cohort in the parent study (see Table 1) $[2,4]$.

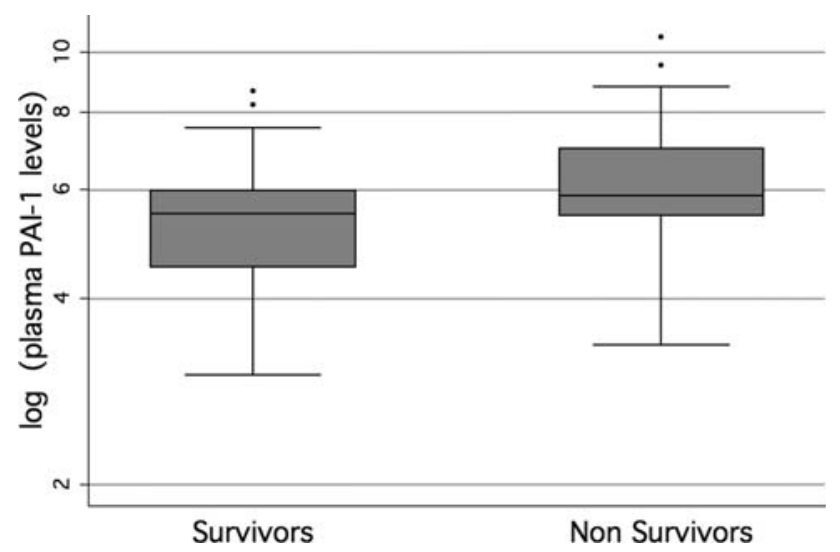

Fig. 1 Boxplots of log-transformed day 1 plasma levels of plasminogen activator inhibitor-1 (PAI-1) stratified by 28-day mortality among 94 pediatric patients with acute lung injury (ALI) There was a statistically significant difference in the levels between survivors and nonsurvivors $(P<0.01)$

\section{Primary outcome (mortality)}

A total of $14 / 94(15 \%)$ patients died prior to hospital discharge. The primary diagnosis, associated multiorgan failure and attributable causes of death are listed in Table 2. PAI-1 levels were higher among nonsurvivors than among survivors. Among nonsurvivors, the median PAI-1 level was $350 \mathrm{ng} / \mathrm{mL}$ with an interquartile range from 232 to $1,083 \mathrm{ng} / \mathrm{mL}$, whereas among the survivors the median PAI-1 level was $239 \mathrm{ng} / \mathrm{mL}$ with the interquartile range from 90 to $393 \mathrm{ng} / \mathrm{mL}$. Due to their nonnormal distribution, PAI-1 levels were log-transformed before applying parametric tests to compare the levels between survivors and nonsurvivors (Fig. 1). There was a statistically significant difference between PAI-1 levels among survivors and nonsurvivors $(P<0.01)$. Using multivariate logistic regression to adjust for age and the severity of illness, the odds of mortality increased by 2.0 for every $\log$ increase in the level of plasma PAI-1 (Table 3). There was no statistically significant difference in PAI-1 levels based on the primary diagnoses.

\section{Secondary outcome (VFD)}

Ventilator-free days were calculated as the number of days of unassisted breathing between enrollment on day 0 until day 28 when the patient was alive [19]. Increasing PAI-1 levels were correlated with the need for prolonged mechanical ventilation. Spearman's correlation was $\rho=-0.26(P<0.02)$. The number of VFDs was lower among patients with increasing quartiles of plasma PAI-1 levels $(P<0.02)$ (Fig. 2). By multivariate linear regression that was adjusted for age and severity of illness, there

Table 2 Diagnosis, multiorgan failure, and cause of death among nonsurvivors

\begin{tabular}{lll}
\hline Primary diagnosis & Multi-organ failure & Final cause of death \\
\hline $\begin{array}{l}\text { Leukemia } \\
\text { Lupus flare }\end{array}$ & ARDS, CV, heme, renal & Brain death \\
Pneumonia (pneumococcal) & ARDS, renal, hep, GI, heme, & $\begin{array}{l}\text { Brain death } \\
\text { Cardiac arrest with } \\
\text { clinical herniation }\end{array}$ \\
$\begin{array}{l}\text { Vasoocclusive disease and graft-versus-host } \\
\quad \text { disease after BMT }\end{array}$ & No escalation of care \\
Sepsis and candida superinfection & ARDS, hepatic, renal, heme, CV & No escalation of care \\
Sepsis (pneumococcal) & ARDS, CV, heme, hep, renal & Withdrawal of support \\
Pneumonia (influenza A and candida) & ARDS, CV, renal, hepatic, heme, CNS & Withdrawal of support \\
Sepsis (strept viridans) & ARDS, heme, renal, liver & Withdrawal of support \\
Cardiac arrest, pulmonary HTN & ARDS, CV, heme, GI & Withdrawal of nitric oxide \\
Adenoviral pneumonia & ARDS, CV, hepatic & Withdrawal of support \\
Aspiration pneumonia & ARDs, bleeding on ECLS & Withdrawal of support \\
Meningococcemia with peripheral ischaemia & ARDS, heme & Withdrawal of support \\
Head trauma & ARDS, renal, CV, heme, hep, CNS & No escalation of care \\
Sickle cell disease, stroke, desferoxmine toxicity & ARDS, CV, heme & Withdrawal of support \\
\hline
\end{tabular}

$A R D S$ Acute respiratory distress syndrome, $C V$ cardiovascular, heme hematologic failure, hep hepatologic failure, ECLS extracorporeal life support, $C N S$ central nervous system, $G I$ gastrointestinal 
Table 3 Association of ventilator-free days and mortality and PAI-1

\begin{tabular}{|c|c|c|c|c|}
\hline \multirow{2}{*}{$\begin{array}{l}\text { Predictor } \\
\text { log PAI-1 } \\
\text { levels }\end{array}$} & \multicolumn{2}{|l|}{$\begin{array}{l}\text { Linear regression } \\
\text { outcome: VFD }\end{array}$} & \multicolumn{2}{|c|}{$\begin{array}{l}\text { Logistic regression } \\
\text { outcome: mortality }\end{array}$} \\
\hline & $\begin{array}{l}\text { Coefficient } \\
{[95 \% \mathrm{CI}]}\end{array}$ & $P$ & $\begin{array}{l}\text { Odds ratio } \\
{[95 \% \mathrm{CI}]}\end{array}$ & $P$ \\
\hline $\begin{array}{l}\text { Unadjusted } \\
\text { Adjusted }^{\mathrm{a}}\end{array}$ & $\begin{array}{l}-2.0[-3.4 \text { to } 0.6] \\
-1.6[-2.9 \text { to } 0.3]\end{array}$ & $\begin{array}{l}<0.01 \\
<0.02\end{array}$ & $\begin{array}{l}1.75[1.1-2.6] \\
2.0[1.04-3.0]\end{array}$ & $\begin{array}{l}<0.01 \\
<0.02\end{array}$ \\
\hline
\end{tabular}

${ }^{a}$ Adjusted for age and PRISM III

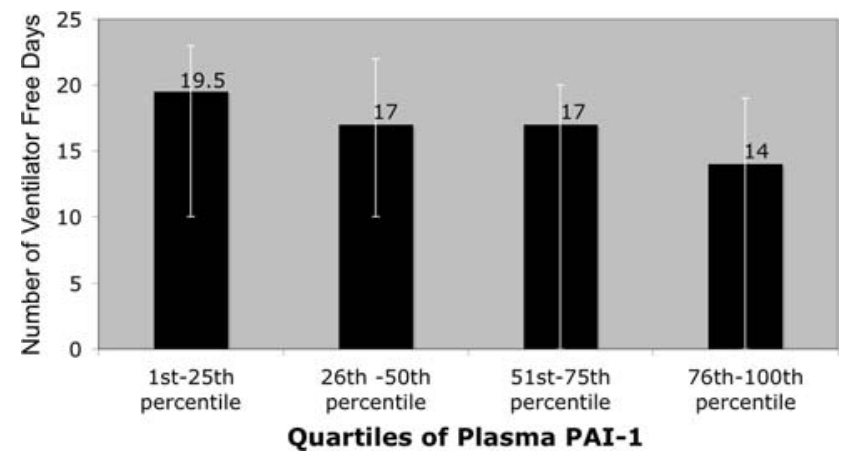

Fig. 2 Number of ventilator-free days (VFD) among patients stratified by quartiles of plasma levels of plasma plasminogen activator inhibitor-1 (PAI-1). The height of the bar represents the median and the error bars represent the interquartile range (25th75 th percentile) of the number of VFDs in each stratum of patients. There was a decrease in the number of VFDs with increasing levels of plasma PAI-1 (trend test $P<0.02$ )

was a decrease of 1.6 VFD for each log increase in PAI-1 levels (Table 3).

\section{Discussion}

The important findings from this prospective study of 94 pediatric patients with ALI are that elevated plasma levels of PAI-1 are associated with increased mortality and fewer VFDs in pediatric patients with ALI, independent of age and severity of illness. These results expand upon prior findings in adults from an earlier study that examined the relationship of plasma PAI-1 levels to clinical outcomes in a cohort of 779 patients with ALI [9]. The study by Ware and colleagues reported that among adults with ALI, the odds of mortality increased by 2.0 for every log increase in the level of PAI-1. In this study of children with ALI, we found that the adjusted odds of mortality increased by 2.0 for every log increase in the level of plasma PAI-1 after adjustment for age and severity of illness.

Early elevation of plasma PAI-1 could be a useful biomarker of prognosis in pediatric patients with ALI because the association of elevated plasma PAI-1 levels with clinical outcomes was independent of age and severity of illness at the time of presentation. Biomarkers of prognosis can have value because they may help identify patients who are at the greatest risk for poor clinical outcomes, allowing therapeutic and preventive interventions to be directed towards these more susceptible patients. In addition, if causality can be established in future studies, the biomarkers may provide targets for pharmacologic intervention.

Intra-alveolar fibrin deposition, which is a pathologic hallmark of ALI, may exert beneficial effects by sealing leakage sites when the capillary endothelium and alveolar epithelial barrier are compromised. However, severe and persistent fibrin deposition can have deleterious effects [10-14, 20-26]. Tissue-type and urokinase-type plasminogen activators (uPA) activate plasminogen to form plasmin, which degrades fibrin. PAI-1 is an endogenous inhibitor of the plasminogen activators and therefore elevation of PAI-1 may lead to an unfavorable balance of fibrin deposition and fibrinolysis [27, 28]. In addition, uPA has a role in migration of inflammatory cells [29]. PAI-1 also directly inhibits integrin-mediated cell migration and thereby has a direct effect on the host immune response as well [30, 31].

There are some limitations to this study. It was carried out by combining subsets of patients from two prospective studies of ALI in whom plasma samples were available. We combined patients from two studies because there were not enough patients with plasma samples collected in either of the studies individually. Both studies prospectively identified patients with ALI using the AECC criteria for definition of ALI. The distributions of predisposing conditions leading to ALI and baseline demographics of the enrolled patients were similar in the two studies (Table 1). There was a difference in the overall mortality in the two studies, which probably is a reflection of historic trends of improving mortality in ALI, most likely due to increasing use of lung-protective ventilation strategies, and of the different exclusion criteria in the two studies. The prone positioning study excluded patients with cardiovascular instability [2]. We believe that patients with plasma samples included in the present study are a true representation of each of the parent studies because the $\mathrm{PaO}_{2} / \mathrm{F}_{\mathrm{i}} \mathrm{O}_{2}$, PRISM scores, and VFDs among the subsets of patients for whom plasma samples were available (and thus included in this study) were not statistically different from the $\mathrm{PaO}_{2} / \mathrm{F}_{\mathrm{i}} \mathrm{O}_{2}$, PRISM scores, and VFDd for patients enrolled in each of the parent studies.

In conclusion, the results from this study indicate that early elevation of plasma PAI-1 is associated with higher mortality and fewer VFDs among pediatric patients with ALI, independent of age and severity of illness. These findings support a likely role of altered fibrinolysis in the pathogenesis of pediatric ALI and they also suggest that elevated plasma PAI-1 may be a useful biomarker of prognosis in patients with ALI. In addition, if causality 
can be established in future studies, PAI-1 may be a target for future pharmacologic intervention.

Acknowledgments Supported by NHLBI K23HL085526-01 (Anil Sapru), NICHD K23 RR 15543 (Heidi Flori), NICHD RO1 NR 005336 (Martha A.Q. Curley), and NICHD RR 1271 (Pediatric Clinical Research Centre).

\section{Conflict of interest statement None.}

Open Access This article is distributed under the terms of the Creative Commons Attribution Noncommercial License which permits any noncommercial use, distribution, and reproduction in any medium, provided the original author(s) and source are credited.

\section{References}

1. Ware LB, Matthay MA (2000) The acute respiratory distress syndrome. N Engl J Med 342:1334-1349

2. Curley MA, Hibberd PL, Fineman LD, Wypij D, Shih MC, Thompson JE, Grant MJ, Barr FE, Cvijanovich NZ, Sorce L, Luckett PM, Matthay MA, Arnold JH (2005) Effect of prone positioning on clinical outcomes in children with acute lung injury: a randomized controlled trial. JAMA 294:229-237

3. Dahlem P, van Aalderen WM, Bos AP (2007) Pediatric acute lung injury. Paediatr Respir Rev 8:348-362

4. Flori HR, Glidden DV, Rutherford GW, Matthay MA (2005) Pediatric acute lung injury: prospective evaluation of risk factors associated with mortality. Am J Respir Crit Care Med 171:9951001

5. Kneyber MC, Brouwers AG, Caris JA, Chedamni S, Plotz FB (2008) Acute respiratory distress syndrome: is it underrecognized in the pediatric intensive care unit? Intensive Care Med 34:751-754

6. Willson DF, Thomas NJ, Markovitz BP, Bauman LA, DiCarlo JV, Pon S, Jacobs BR, Jefferson LS, Conaway MR, Egan EA (2005) Effect of exogenous surfactant (calfactant) in pediatric acute lung injury: a randomized controlled trial. JAMA 293:470-476

7. Randolph AG (2009) Management of acute lung injury and acute respiratory distress syndrome in children. Crit Care Med 37:2448-2454

8. Zimmerman JJ, Akhtar SR, Caldwell E, Rubenfeld GD (2009) Incidence and outcomes of pediatric acute lung injury. Pediatrics 124:87-95

9. Ware LB, Matthay MA, Parsons PE, Thompson BT, Januzzi JL, Eisner MD (2007) Pathogenetic and prognostic significance of altered coagulation and fibrinolysis in acute lung injury/acute respiratory distress syndrome. Crit Care Med 35:1821-1828

10. Bertozzi P, Astedt B, Zenzius L, Lynch K, LeMaire F, Zapol W, Chapman HA Jr (1990) Depressed bronchoalveolar urokinase activity in patients with adult respiratory distress syndrome. N Engl J Med 322:890-897
11. Determann RM, Millo JL, Garrard CS, Schultz MJ (2006) Bronchoalveolar levels of plasminogen activator inhibitor-1 and soluble tissue factor are sensitive and specific markers of pulmonary inflammation. Intensive Care Med 32:946-947

12. El Solh AA, Bhora M, Pineda L, Aquilina A, Abbetessa L, Berbary E (2006) Alveolar plasminogen activator inhibitor-1 predicts ARDS in aspiration pneumonitis. Intensive Care Med 32:110-115

13. Idell S, James KK, Levin EG, Schwartz BS, Manchanda N, Maunder RJ, Martin TR, McLarty J, Fair DS (1989) Local abnormalities in coagulation and fibrinolytic pathways predispose to alveolar fibrin deposition in the adult respiratory distress syndrome. J Clin Invest 84:695-705

14. Nakstad B, Lyberg T, Skjonsberg OH, Boye NP (1990) Local activation of the coagulation and fibrinolysis systems in lung disease. Thromb Res 57:827-838

15. Vadasz I, Morty RE, Olschewski A, Konigshoff M, Kohstall MG, Ghofrani HA, Grimminger F, Seeger W (2005) Thrombin impairs alveolar fluid clearance by promoting endocytosis of $\mathrm{Na}^{+}, \mathrm{K}^{+}$-ATPase. Am J Respir Cell Mol Biol 33:343-354

16. Prabhakaran P, Ware LB, White KE, Cross MT, Matthay MA, Olman MA (2003) Elevated levels of plasminogen activator inhibitor-1 in pulmonary edema fluid are associated with mortality in acute lung injury. Am J Physiol Lung Cell Mol Physiol 285:L20-L28

17. Bernard GR, Artigas A, Brigham KL, Carlet J, Falke K, Hudson L, Lamy M, Legall JR, Morris A, Spragg R (1994) The American-European Consensus Conference on ARDS. Definitions, mechanisms, relevant outcomes, and clinical trial coordination. Am J Respir Crit Care Med 149:818-824

18. Lang IM, Marsh JJ, Olman MA, Moser KM, Schleef RR (1994) Parallel analysis of tissue-type plasminogen activator and type 1 plasminogen activator inhibitor in plasma and endothelial cells derived from patients with chronic pulmonary thromboemboli. Circulation 90:706-712
19. Schoenfeld D (2002) Statistical evaluation of ventilator-free days as an efficacy measure in clinical trials of treatments for acute respiratory distress syndrome. Crit Care Med 30:17721777

20. Chapman HA, Allen CL, Stone OL (1986) Abnormalities in pathways of alveolar fibrin turnover among patients with interstitial lung disease. Am Rev Respir Dis 133:437-443

21. Choi G, Schultz MJ, van Till JW, Bresser P, van der Zee JS, Boermeester MA, Levi M, van der Poll T (2004) Disturbed alveolar fibrin turnover during pneumonia is restricted to the site of infection. Eur Respir J 24:786789

22. Gunther A, Mosavi P, Heinemann S, Ruppert C, Muth H, Markart P, Grimminger F, Walmrath D, Temmesfeld-Wollbruck B, Seeger W (2000) Alveolar fibrin formation caused by enhanced procoagulant and depressed fibrinolytic capacities in severe pneumonia. Comparison with the acute respiratory distress syndrome. Am J Respir Crit Care Med 161:454-462

23. Olman MA WL, Simmons WL, White KE, Matthay MA (2001) Pulmonary edema fluid levels of type 1 plasminogen activator inhibitor (PAI-1) predict a poor prognosis in clinical acute lung injury. Am J Respir Crit Care Med 163

24. Schultz MJ, Millo J, Levi M, Hack CE, Weverling GJ, Garrard CS, van der Poll $\mathrm{T}$ (2004) Local activation of coagulation and inhibition of fibrinolysis in the lung during ventilator associated pneumonia. Thorax 59:130 135

25. Song Y, Lynch SV, Flanagan J, Zhuo $\mathrm{H}$, Tom W, Dotson RH, Baek MS, Rubio-Mills A, Singh G, Kipnis E, Glidden D, Brown R, Garcia O, Wiener-Kronish JP (2007) Increased plasminogen activator inhibitor-1 concentrations in bronchoalveolar lavage fluids are associated with increased mortality in a cohort of patients with Pseudomonas aeruginosa. Anesthesiology 106:252-261 
26. Ware LB, Eisner M, Wickersham N, Olman MA, Thompson B, Parsons P, Matthay MA (2004) Plasminogen activator inhibitor-1 (PAI-1), a marker of impaired fibrinolysis, is associated with higher mortality in patients with ALI/ARDS. Am J Respir Crit Care Med 169:A115

27. Hoekstra T, Geleijnse JM, Schouten EG, Kluft C (2004) Plasminogen activator inhibitor-type 1: its plasma determinants and relation with cardiovascular risk. Thromb Haemost 91:861-872
28. Horrevoets AJ (2004) Plasminogen activator inhibitor 1 (PAI-1): in vitro activities and clinical relevance.

Br J Haematol 125:12-23

29. Gyetko MR, Chen GH, McDonald RA, Goodman R, Huffnagle GB, Wilkinson CC, Fuller JA, Toews GB (1996) Urokinase is required for the pulmonary inflammatory response to Cryptococcus neoformans. A murine transgenic model. J Clin Invest 97:1818-1826
30. Sitrin RG, Shollenberger SB, Strieter RM, Gyetko MR (1996) Endogenously produced urokinase amplifies tumor necrosis factor-alpha secretion by THP1 mononuclear phagocytes. J Leukoc Biol 59:302-311

31. Sitrin RG, Todd RF III, Albrecht E, Gyetko MR (1996) The urokinase receptor (CD87) facilitates $\mathrm{CD} 11 \mathrm{~b} /$ CD18-mediated adhesion of human monocytes. J Clin Invest 97:1942-1951 